\title{
Model Vehicle Routing Problem dengan Karakteristik Rute Majemuk, Multiple Time Windows, Multiple Products dan Heterogeneous Fleet untuk Depot Tunggal
}

\author{
Ary Arvianto $^{1 *}$, Aditya Hendra Setiawan ${ }^{1}$, Singgih Saptadi ${ }^{1}$
}

\begin{abstract}
In this paper we developed a VRP model for multiple routes, multiple time windows for multiple products and heterogeneous vehicles. The solution were constructed using a heuristic approach, i.e, a sequential insertion algorithm. Additionally, this model is applied to solve fuel distributions for eight customers in East Nusa Tenggara. It needs two tankers with capacity of 4700 kilo liters, so that those distributions can be accomplished with a minimum number of vehicles, total completion time, and range of completion time. The result of this study shows that for a heterogeneous vehicles problem, a vehicle with the largest capacity may not necessarily be the vehicle that provides an optimal solution. Moreover, advance trials should be conducted by providing a limited number of tankers for each tanker capacity, so the description of heterogeneous vehicles becomes more visible. In the future research, the solution will be improved by utilizing relocation techniques.
\end{abstract}

Keywords: VRP, route selection, heterogeneous fleet, multiple time windows, Sequential Insertion.

\section{Pendahuluan}

Dalam melakukan pengiriman barang, perusahaan harus mampu menentukan konfigurasi jalur distribusi dengan tepat supaya pengiriman menjadi cepat dan tidak memakan biaya yang banyak. Penentuan konfigurasi ini harus mempertimbangkan strategi distribusi yang sesuai dengan karakteristik perusahaan. Permasalahan sistem distribusi dari suatu perusahaan merupakan faktor penting yang melibatkan beberapa pertimbangan utama. Bodin et al (1983) menyebutkan bahwa beberapa pertimbangan utama tersebut antara lain adalah pemilihan rute kendaraan, armada kendaraan, sampai pada penjadwalan kendaraan. Pertimbangan utama inilah yang sekarang dikenal dengan istilah Vehicle Routing Problem (VRP).

VRP secara umum diartikan sebagai masalah penentuan rute bagi sejumlah kendaraan yang bertujuan untuk meminimasi biaya transportasi total dan memenuhi sejumlah batasan yang mencerminkan karakteristik dari situasi nyata (Gendreau et al. [2]). Batasan inilah yang harus dijadikan pertimbangan bagi stakeholder perusahaan nantinya agar dapat menekan biaya operasional perusahaan, khususnya yang berkaitan dengan

\footnotetext{
${ }^{1}$ Fakultas Teknik, Program Studi Teknik Industri, Universitas Diponegoro, J. Prof. Sudharto, Tembalang, Semarang 50239, Indonesia. Email: aryarvi@yahoo.com, adityahendras@gmail.com, singgihs@gmail.com.

* Penulis korespondensi
}

transportasi. Brasy [3] menyatakan bahwa permasalahan VRP dapat didefinisikan sebagai permasalahan pencarian rute distribusi dengan ongkos minimal dari satu depot ke pelanggan yang letaknya tersebar dengan jumlah permintaan (demand) yang berbeda-beda. Tiap rute dibuat sedemikian rupa sehingga tiap pelanggan hanya boleh dilayani oleh satu kendaraan (vehicle) saja. Hal ini dilakukan dengan mempertimbangkan kapasitas kendaraan dalam satu kali angkut agar biaya yang dikeluarkan juga dapat ditekan seminimal mungkin. Biasanya penentuan biaya yang minimal sangat bergantung pada biaya bahan bakar dan jarak tempuh yang akan dilalui oleh kendaraan tersebut.

Bentuk dasar VRP adalah menganggap bahwa semua kendaraan yang dimiliki mempunyai kapasitas yang sama (homogen). Padahal dalam Kenyataannya, perusahaan tidak selalu mempunyai armada dengan kapasitas angkut yang sama. Perusahaan, baik itu perusahaan yang besar maupun yang kecil sekalipun pasti mempunyai kendaraan dengan kapasitas yang berbeda, sehingga metode penyelesaian VRP klasik sekarang ini susah untuk diterapkan. Oleh karena itu muncul varian VRP baru yang untuk menyelesaikan permasalahan dengan jenis dan kapasitas kendaraan yang berbeda, yaitu yang dikenal dengan istilah Heterogeneous Fleet Vehicle Routing Problem (HFVRP).

Belmecheri et al. [4] berpendapat bahwa pada masa sekarang ini hampir semua industri mempunyai kendaraan dengan kapasitas yang berbeda-beda. 
Kendaraan tersebut mempunyai spesifikasi dan jenis yang berbeda, sehingga daya tampungnya pun juga berbeda. Selain itu dari masing-masing kendaraan juga mempunyai jumlah armada yang terbatas. Belfiore dan Yoshizaki [5] menambahkan bahwa tujuan dari varian VRP yang mempertimbangkan kendaraan yang heterogen (Heterogeneous Fleet) adalah untuk meminimasi biaya tetap kendaraan dan biaya variabel rute yang ditempuh. Biaya tetap kendaraan adalah biaya yang dikeluarkan untuk biaya pembelian kendaraan dan biaya perawatan, sedangkan biaya variabel rute berhubungan dengan biaya yang dikeluarkan untuk menempuh rute perjalanan pada saat kendaraan tersebut mengirimkan barang.

Subramanian [6] menyebutkan bahwa tujuan dari diikutsertakannya faktor kendaraan yang heterogen adalah agar diketahui penggunaan kendaraan yang tepat sesuai dengan rute dan demand yang sesuai dengan pelanggan agar didapat biaya yang paling minimal dan tidak boros penggunaan sumber daya kendaraan yang dimiliki. Pertimbangan perbedaan kapasitas kendaraan yang berbeda ini dengan pertimbangan bahwa suatu perusahaan pasti mempunyai kendaraan yang mempunyai kapasitas yang berbeda.

Penelitian tentang VRP telah dilakukan oleh Suprayogi [7] yaitu VRP Multiple Trips and Time Windows (VRPMTTW), dimana operasi yang dilakukan adalah pickup dan loading, serta mempertimbangkan single time windows. Penelitian tersebut kemudian dilanjutkan oleh Imawati [8] dengan menambahkan tiga fungsi tujuan yaitu meminimumkan jumlah kendaraan, waktu durasi total dan rentang waktu durasi. Imawati [8] menerapkan teknik local search (LS) untuk memecahkan masalah varian VRPMTTW tersebut.

Arvianto [9] telah mengembangkan model VRP distribusi barang dengan loading dan unloading depot tunggal, dengan varian split delivery, multiple products and compartements, multiple trips, dan multiple time windows. Namun untuk model yang dibuat masih menggunakan varian kendaraan yang homogen, sehingga belum bisa mengakomodir kebutuhan perusahaan yang mempunyai banyak varian jenis dan kapasitas kendaraan. Model yang dikembangkan oleh Arvianto [9] mempunyai tujuan utama untuk meminimasi fungsi beban tertimbang yang dilihat dari faktor jumlah kendaraan yang digunakan dan total waktu penyelesaian pendistribusian barang. Faktor biaya belum diperhatikan dalam model tersebut.

Belmeccheri et al. [4] sudah mampu mengembangkan model VRP dengan varian kendaraan yang heterogen, namun model yang dikembangkan belum mempertimbangkan varian split delivery, multiple products and compartements, dan multiple trips. Tujuannya yang ingin dicapai juga untuk mengetahui jumlah kendaraan yang paling optimal untuk digunakan dalam proses penditribusiannya.

Penelitian ini adalah penelitian lanjutan dari Arvianto [9] dan Belmecherri et al. [4] yang mencoba untuk mengembangkan algoritma baru penentuan rute dan jadwal kendaraan mengenai permasalahan VRP dengan mengkombinasikan model yang telah dibuat keduanya, yaitu penambahan varian baru yang mempertimbangkan jenis kendaraan dengan kapasitas yang berbeda (heterogeneous fleet) yang kemudian ditambahkan pada varian split delivery, multiple products and compartements, multiple trips, dan multiple time windows dengan tujuan untuk meminimasi beban tertimbang dan minimasi biaya yang dikeluarkan dalam proses pengiriman produk. Batasan time windows yang digunakan bersifat soft, artinya ketika waktu akhir discharging di suatu node harus melebihi batas akhir (jam tutup) node tersebut maka proses discharging harus diselesaikan sesuai dengan penjelasan di atas, maka diperlukan suatu pengembangan algoritma perencanaan VRP yang mempertimbangkan varian heterogeneous fleet, split delivery, multiple products and compartements, multiple trips, dan multiple time windows.

Penelitian ini mencoba untuk melengkapi masalah varian VRP yang telah diteliti dan dikembangkan oleh Arvianto [9] dengan menambahkan karakterisitik baru, yaitu heterogeneous fleet pada kasus VRP. Penambahan varian baru ini dengan mengadopsi hasil penelitian Belfiore dan Yoshizaki [5]; Belmecheri et al. [4].

Varian VRP yang dipertimbangkan pada penelitian ini adalah:

- Multiple trips (satu kendaraan dapat melayani lebih dari satu rute dalam satu periode perencanaan pengiriman).

- Multiple products and multiple compartements (jenis produk yang dikirimkan dan kendaraan yang dipakai untuk mengirim produk memiliki kompartemen lebih dari satu),

- Multiple time windows (adanya mekanisme jam buka dan jam tutup sesuai dengan pelanggan lebih dari satu dalam periode perencanaan).

- Split delivery (pengiriman produk kepada satu pelanggan dapat dibagi oleh satu atau beberapa kendaraan).

- Heterogeneous fleet (pengiriman produk dilakukan menggunakan ken-daraan dengan jenis dan kappasitas yang berbeda). 
Tahap penentuan rute dan jadwal kendaraan distribusi terdiri dari tahapan identifikasi masalah, pengumpulan data, karakteristik sistem, pengembangan model, contoh numerik, dan analisis hasil. Berikut ini akan disajikan tahapan karakterisasi sistem dan pengembangan model.

\section{Metode Penelitian}

\section{Karakterisasi Sistem}

Penelitian ini fokus pada distribusi produk antara depot dan konsumen. Data penelitian diambil dari Yudistira et al. [10], yaitu proses distribusi BBM di Kupang, Nusa Tenggara Timur. Produk yang didistribusikan terdiri dari premium, solar, dan minyak tanah. Dalam penelitian ini terdapat sembilan pelabuhan yang terdiri dari satu depot supply point dan delapan pelanggan destination point.

Setiap hari pelabuhan memiliki throughput atau tingkat konsumsi bahan bakar minyak per hari dimana masing-masing pelanggan berbeda-beda. Kondisi ini akan mengakibatkan pelabuhan memiliki waktu dimana suatu pelabuhan akan mengalami kekurangan stok. Berdasarkan data permintaan, diperoleh informasi bahwa periode perencanaan yang dipakai adalah 7 hari, karena daya tahan stok terkecil adalah 7,1 hari di pelanggan Atapupu.

Ketiga produk didistribusikan oleh kapal tanker yang didalamnya terdapat cargo oil tank group segregation yang akan dibagi untuk ketiga produk tersebut. Total kapasitas cargo ini yang selanjutnya disebut sebagai kapasitas total kapal tanker.

Distributor mempunyai 3 jenis kapal yang akan digunakan dalam pengiriman BBM, yaitu kapal dengan kapasitas 8.750 kiloliter, 4.700 kiloliter, dan 2.000 kiloliter dengan asumsi jumlah ketersediaan tidak terbatas untuk masing-masing jenis kapal. Kondisi heterogen ini mengacu dalam Belfiore dan Yoshizaki [5] dan disebut sebagai kondisi infinite.

Dari masing-masing kapal terdiri dari 3 kompartemen dengan pembagian kompartemen adalah sebagai berikut: Grup cargo pertama 20\% dari kapasitas total untuk produk premium. Grup cargo kedua 30\% dari kapasitas total untuk produk solar. Grup cargo ketiga 50\% dari kapasitas total untuk bahan bakar minyak tanah.

Kecepatan kapal yang digunakan adalah $10 \mathrm{knot} /$ jam. Kecepatan aliran untuk loading/discharging produk adalah 200 kiloliter/jam dan waktu setup untuk loading/discharging produk adalah selama 2 jam.

\section{Model Konseptual Penelitian}

Model yang akan dikembangkan dalam pendistribusian produk ini mempunyai beberapa batasan.

\section{Heterogeneous Fleet}

Kapal yang dimiliki mempunyai kapasitas yang berbeda-beda. Masing-masing kapal juga mempunyai batasan yang berbeda, baik itu dilihat dari ukuran kapasitas muatan, biaya tetap per kapal, dan lainnya.

\section{Multiple Trips}

Satu kapal dapat melayani satu atau lebih pelanggan/rute dalam satu kali tur pengiriman produk.

\section{Multiple Products and Compartements}

Kapal yang dimiliki mempunyai kompartemen lebih dari satu dan jenis produk yang dikirimkan lebih dari satu macam produk. Masing-masing produk diletakkan di kompartemen yang spesifik agar tidak bercampur dengan produk lain dalam satu kapal.

\section{Split Delivery}

Pengiriman produk kepada pelanggan dapat langsung dikirim dalam satu kali pengiriman (entirely delivery) maupun beberapa kali proses pengiriman (partial delivery).

\section{Multiple Time Windows}

Adanya mekanisme jam buka dan tutup lebih dari satu dalam satu periode perencanaan.

Proses pengumpulan data ini dilakukan dengan cara mengambil data hasil penelitian dari Yudhistira et al. [10] yang dijadikan rujukan utama dalam pengembangan, verifikasi, dan validasi terhadap hasil perhitungan. Data yang digunakan adalah data demand pelanggan, jam buka dan tutup pelanggan, serta data jarak dan waktu perjalanan antar pelanggan.

Untuk data lain yang digunakan adalah data mengenai jenis dan kapasitas kapal menggunakan Data Kapal PT. Pertamina yang diambil dari Laporan Tahunan PT. Pertamina Tahun 2012. Data tersebut meliputi jenis kapal, kapasitas, kecepatan bongkar muat, dan kecepatan laju kapal.

\section{Formulasi Matematis}

Sesuai dengan karakteristik pendistribusian dan model konseptual pada Gambar 1, maka dapat 
dibuatlah model matematis yang akan digunakan $a_{i}^{h}$ sebagai penterjemah algoritma.

Indeks

$i \quad:$ indeks lokasi; $i=0$ adalah $\operatorname{depot}, i=1,2, \ldots, N$ adalah pelanggan

$t \quad:$ indeks tur, $t=1,2,3, \ldots, N T$

$r \quad:$ indeks rute, $r=1,2,3, \ldots, N R_{[\mathrm{t}]}$

$p$ : indeks produk, $p=0,1, \ldots, N P$

$k$ : indeks posisi, $k=1,2, \ldots, N L[t, r]$

$z \quad$ : indeks jenis kapal; $\mathrm{z}=1,2, \ldots, Z$

Parameter

$N$ : jumlah dari set pelanggan $i$

$N P$ : jumlah jenis produk

$q_{L_{t z, r, k} p} \quad:$ besarnya permintaan produk $p$ pada lokasi yang mempunyai posisi $k$, rute $r$, dan tur $t$ kapal $\mathrm{z}$ (satuan volume)

Ws : waktu setup (satuan waktu)

LT : kecepatan loading (satuan: jumlah produk persatuan waktu)

DT : kecepatan discharging (satuan: jumlah produk per satuan waktu)

$v_{z} \quad$ : kecepatan kapal $z$ (satuan: jarak persatuan waktu)

$\tau_{\left[L_{t, z, r, k}\right],\left[L_{t, z, r, k+1}\right]}$ : waktu perjalanan antara lokasi $k$ ke lokasi $k+1$, pada rute $r$, tur $t$ kapal $z$ (satuan waktu)

$Q_{z}[p]$

: kapasitas kompartemen untuk produk $p$ pada kapal $z$ (multiple compartemens) $b_{i}^{h}$

$H$

Variabel

NV : jumlah total kapal (satuan unit)

NTz : jumlah tur kapal $z$

$N R_{[t, z]} \quad:$ jumlah rute dalam tur $t$ oleh kapal $z$

$N L_{[t, z, r]} \quad$ : jumlah lokasi pada rute $r$ dalam tur $t$ oleh kapal $z$

$L_{t, z, r, k} \quad$ : lokasi pada posisi $k$, rute $r$ dalam tur $t$ kapal $z$

$b_{L_{t, z}, r} \quad$ : besarnya muatan yang diantarkan didalam rute $r$, tur $t$ kapal $z$ untuk untuk produk $p$ (satuan volume)

$y_{L_{t, z, r, k} p} \quad:$ proporsi pengiriman muatan produk $p$ pada rute $r$, tur $t$ kapal $z$ dan lokasi k

$J m_{\mathrm{L}[t, z, r, k]} \quad$ : saat keberangkatan pada posisi $k$ di tur $t$ kapal $z$, dan rute $r$ (satuan waktu)

Wp : waktu perjalanan (satuan waktu)

$J t_{\mathrm{L}[t, z, r, k]} \quad$ : saat tiba yang terjadi pada posisi $k \mathrm{di}$ tur $t$ kapal $z$, dan rute $r$ (satuan waktu)

$W t_{\mathrm{L}[t, z, r, k} \quad$ : waktu tunggu pada posisi $k$ di tur $t$ kapal $z$, dan rute $r$ (satuan waktu)

WLT : waktu loading (satuan waktu)
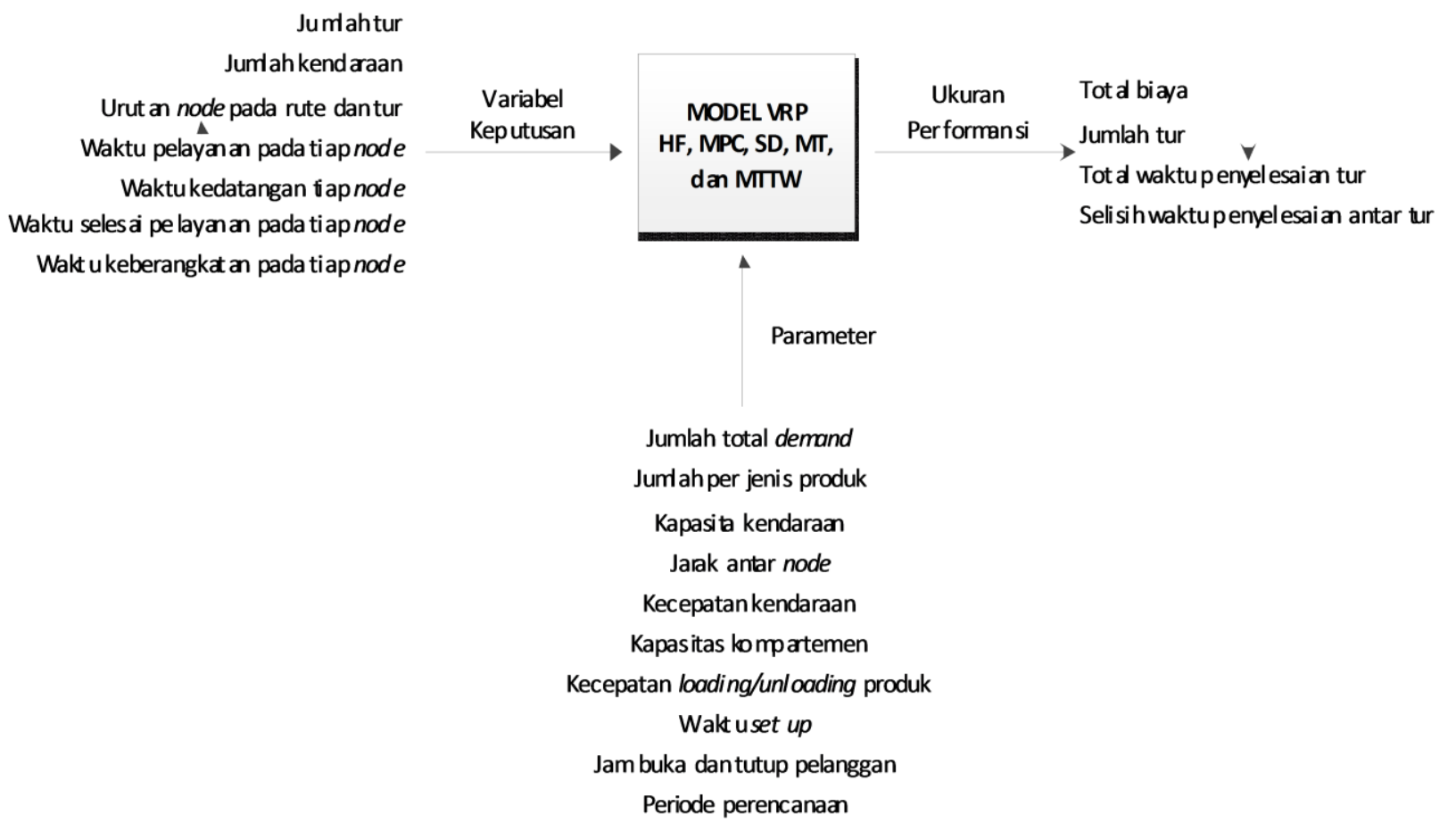

Gambar 1. Model konseptual penelitian 


$\begin{array}{ll}\text { WDT } & : \text { waktu discharging (satuan waktu) } \\ J_{S \mathrm{~L}[t, z, r, N L[t, z, r]}: & \text { saat selesai pada posisi } N L[t, r] \text { di tur } \\ & t \text { kapal } z \text {, dan rute } r \text { (satuan waktu) } \\ C_{[\mathrm{t}, \mathrm{z}]} & : \text { waktu penyelesaian tur } t \text { oleh kapal } z \\ & \text { (satuan waktu) } \\ \mathrm{TCT} & : \text { total waktu penyelesaian tur (satuan } \\ & \text { waktu) } \\ \mathrm{RCT} & : \text { rentang waktu penyelesaian tur (satu- } \\ & \text { an waktu) } \\ \mathrm{TCD} & : \text { Total Ongkos Distribusi } \\ C_{S K} & : \text { Biaya tetap kapal } \\ C_{B B} & : \text { Biaya bahan bakar per km } \\ C_{L} & : \text { Biaya loading unloading produk per } \\ & \text { unit } \\ C_{G} & : \text { Gaji sopir per kunjungan } \\ C_{M} & : \text { Akomodasi perjalanan } \\ C_{R} & : \text { Rupiah retribusi jalan per kapal per } \\ & \text { tur }\end{array}$

\section{Fungsi Tujuan}

Permasalahan pada penelitian ini berkaitan dengan fungsi tujuan majemuk yaitu meminimumkan jumlah kapal $N V$, meminimumkan waktu total penyelesaian $T C T$ dan memimumkan rentang waktu total penyelesaian $R C T$. Fungsi tujuan $R C T$ dimaksudkan untuk memperkecil perbedaan antara waktu total penyelesaian tur terpanjang dengan waktu total penyelesaian tur terpendek sehingga terjadi keseimbangan antar tur. Fungsi tujuan majemuk dalam penelitian ini dilakukan dengan membentuk jumlah tertimbang (weight sum) $N V, T C T$ dan $R C T$ yaitu

$$
\begin{aligned}
\operatorname{Min} f(\theta)= & \omega_{N V} N V(\theta)+\omega_{T C T} T C T(\theta)+ \\
& \omega_{R C T} R C T(\theta)
\end{aligned}
$$

dimana $\theta$ merupakan set solusi, sedangkan bobotbobot $\omega_{N V}, \omega_{T C T}$ dan $\omega_{R C T}$ masing-masing menyatakan bobot untuk fungsi tujuan meminimumkan jumlah kapal $N V$, meminimumkan waktu total penyelesaian $T C T$, dan meminimumkan rentang waktu total penyelesaian tur RCT. Dalam konteks permasalahan ini mempertimbangkan adanya multiple trips, sehingga fungsi tujuan meminimumkan jumlah kapal $N V$ selalu mendapatkan bobot terbesar. Hal ini dikarenakan meminimumkan jumlah kapal merupakan sasaran utama memodelkan aspek multiple trips dalam VRP seperti yang diuraikan dalam Suprayogi [7]. Urutan prioritas kedua dan ketiga tergantung pada preferensi pengambil keputusan. Fungsi ini diperlukan untuk melihat kombinasi tur dan rute terbaik yang dihasilkan dari algoritma dengan mempertimbangkan keseimbangan kerja yang diwakili dengan variabel RCT dan TCT. Fungsi tujuan diatas belum bisa mewakili secara keseluruhan terhadap biaya yang dikeluarkan pada sistem ini.

\section{Minimasi Biaya}

$$
\begin{aligned}
\min \mathrm{TCD}= & \sum_{r=1}^{N R} \sum_{i=0}^{N} \sum_{j=1}^{N+1} C_{S K Z} N_{T Z}+C_{G} N_{R}+ \\
& \sum_{r=1}^{N R} \sum_{z=1}^{Z} C_{B B} V_{Z} W p+3 C_{M} H \quad N_{V}+ \\
& 2 \sum_{r=1}^{N R} \sum_{i=0}^{N} q_{i} C_{L} N_{R}+C_{R} N_{V}
\end{aligned}
$$

Pada fungsi ini digunakan untuk membantu pengambil keputusan untuk mendapatkan berapa biaya yang akan muncul akibat fungsi minimasi tertimbang sebelumnya. Biaya-biaya yang terlibat adalah biaya tetap kendaraan, biaya bahan bakar per kilometer, biaya loading dan unloading barang, biaya retribusi selama di perjalanan, gaji supir, dan biaya komodasi perjalanan.

Permasalahan VRP ini terdiri atas beberapa pelanggan dan sebuah depot tunggal. Himpunan semua pelanggan dan depot disebut node. Waktu perjalanan antar lokasi dinyatakan dengan $\tau_{\left[L_{t, z, r, k}\right],\left[L_{t, z, r, k+1}\right]}$. Tiap pelanggan $i$ memiliki permintaan untuk tiap produk $p$ yaitu $q_{L_{t, z, r}, k}$. Notasi $L_{t, z, r, 1}$ merupakan lokasi depot dimana $i=0$ dan akan berakhir pada lokasi yang sama. Lokasi depot dapat didefinisikan sebagai

$$
\begin{aligned}
L_{t, z, r, 1}=L_{t, z, r, N L[t, r]}= & 0 ; t=1,2, \ldots N T ; z=1,2, \ldots, Z ; \\
& r=1,2, \ldots, N R_{[t]}
\end{aligned}
$$

Untuk lokasi pelanggan didefinisikan sebagai

$L_{t, z, r, k}=i$;

$t=1,2, \ldots N T ; r=1,2, \ldots, N R_{[t]} ;$

$z=1,2, \ldots, Z ; k=2, \ldots N L_{[t, r]}-1 ; i=1,2 \ldots N$

\section{Jumlah Kapal (Number of Vehicles)}

Dalam VRP with multiple trips, setiap kapal melakukan satu tur. Jumlah kapal disimbolkan dengan $N V$. Jika solusi dari permasalahan ini menghasilkan sejumlah tur maka, sejumlah tur tersebut merupakan kebutuhan kapal (tanker). Hal ini disebabkan karena sebuah tanker hanya boleh bekerja sepanjang horison perencanaan. Pernyataan ini dapat ditulis dengan persamaan matematis sebagai berikut:

Jumlah tur kapal jenis $\mathrm{z}=$ Jumlah total kapal $N T z=N V$

Pada model ini, kapal bersifat heterogen. Kapasitas kompartemen untuk produk $p$ pada tiap kapal adalah $Q[p]$ dan kecepatan kapal adalah $v$. Jumlah rute dalam sebuah tur $t(t=1, \ldots, N T)$ adalah $N R_{[t]}$. Jenis kapal $z$ melayani beberapa rute dalam satu tur, atau disebut dengan multiple trips dengan heterogenous fleet sehingga depot memulai perjalanannya untuk rute $r$ dalam tur $t$ yang merupakan depot akhir perjalanan rute sebelumnya $r$-1 dalam tur $t$ yang sama. 
$L_{t, z, r, 1}=L_{t, z, r-1, N L[t, z, r-1]}=0 ; t=1,2, \ldots N T ; z=$

$1,2, \ldots, Z ; r=1,2, \ldots, N R_{[t z]}$

Sebuah tur terdiri dari atas himpunan rute. Dengan $N R_{[\mathrm{tz}]}$ menunjukkan jumlah rute yang terdapat didalam satu tur $t$ oleh kapal z. Suatu rute kapal menggambarkan urutan kunjungan kapal ke pelanggan yang diawali dan kembali lagi ke depot.

Kendala split delivery memastikan bahwa setiap pelanggan akan mendapatkan setidaknya satu kali pengantaran, sehingga permintaan pada lokasi atau pelanggan $i$ dapat dihantarkan dengan lebih dari sekali pengantaran.

$L_{t, z, r, k} \geq 1$;

$t=1,2, \ldots N T ; z=1,2, \ldots, Z ; r=1,2, \ldots, N R_{[t z]}$;

$k=2, \ldots N L_{[t, z, r]}-1$

Muatan pada setiap rute untuk tiap produk harus lebih kecil atau sama dengan kapasitas kompartemen. Dalam hal pengantaran produk, banyaknya muatan tiap kompartemen kapal $b$ yang melayani suatu rute $r$ dalam tur $t$ tidak boleh melebihi kapasitas kompartemen produk $p$.

$b_{L_{t, z, r} p} \leq Q[p], \quad \forall t=1,2, \ldots N T ; z=1,2, \ldots, Z$;

$r=1,2, \ldots N R_{[t, z]} ; p=1,2, \ldots n$

Besarnya muatan yang dibawa tanker dalam tur $t$ oleh kapal $z(t, z)$, rute $r$ untuk produk $p$, jumlahnya kurang atau sama dengan jumlah permintaan pelanggan yang ada didalam rute $r$ dari tur $(t, z)$ untuk produk $p$. Proporsi $y_{L_{t, z, r, k} p}$ terjadi akibat split delivery sehingga mungkin saja demand suatu konsumen dipenuhi dengan lebih dari sekali pengiriman.

$b_{L_{t, z, r} p} \leq \sum_{k=2}^{N L_{[t, z, r]}-1} q_{L_{t, z, r, k} p} \cdot y_{L_{t, z, r, k} p}$

$t=1,2, \ldots N T ; z=1,2, \ldots, Z ; r=1,2, \ldots N R_{[t, z]}$;

$p=1,2, \ldots n$

Pembatas (10) memastikan bahwa setiap pelanggan akan menerima kiriman demand secara penuh.

$\sum_{t=1}^{N T} y_{L_{t, z, r, k} p}=1 ; t=1,2, \ldots N T ; z=1,2, \ldots, Z ;$

$r=1,2, \ldots N R_{[t, z]} ; p=1,2, \ldots n$

Generalisasi dari multiple time windows memastikan bahwa waktu pelayanan yang tersedia $T_{i}$ secara dinamik dan implisit dibatasi oleh batas bawah $a_{i}^{h}$ dan batas atas $b_{i}^{h}$ untuk semua pelanggan $i$.

$\bigwedge_{h=1}^{m_{i}} \neg\left(a_{i}^{h} \leq T_{i} \leq b_{i}^{h}\right), \quad \forall i \in N, m=1,2, \ldots N M$

Pembatas ini menyatakan bahwa $m_{i}$ adalah jumlah holes didalam time windows untuk pelanggan $i$, sehingga $a_{i}^{h}, b_{i}^{h}$ menjadi hole ke- $h$.

\section{Waktu Penyelesaian Tur (Tour Completion Time)}

Waktu penyelesaian suatu tur yang dinyatakan dengan $C T_{[\mathrm{t}, \mathrm{z}]}$, mencakup waktu perjalanan, waktu setup, dan waktu loading/discharging yang terdapat pada tur tersebut. Waktu penyelesaian setiap tur tidak boleh melebihi horison perencanaan.

Waktu penyelesaian tur merupakan waktu yang diperlukan satu kapal untuk menyelesaiakan satu tur yang bisa terdiri dari satu atau beberapa rute. Waktu tur ini merupakan penjumlahan dari waktu perjalanan, waktu setup, waktu loading dan discharging. Waktu penyelesaian tur total (TCT) adalah jumlah dari waktu penyelesaian untuk seluruh tur.

\section{Waktu Perjalanan (Travel Time)}

Waktu perjalanan, $\tau_{\left[L_{t, z, r, k}\right],\left[L_{t, z, r, k+1}\right]}$, merupakan waktu yang dibutuhkan oleh kendaran $z$ mulai dari saat keberangkatan dari suatu lokasi $L_{t, z, r, k}$ hingga sampai lokasi $L_{t, z, r, k+1}$. Kecepatan kapal dan jarak antara lokasi $L_{t, z, r, k}$ dan lokasi $L_{t, z, r, k+1}$ menentukan waktu perjalanan.

$W p=\tau_{[L[t, z, r, k],,[L[t, z, r, k+1]]}$

\section{Waktu Setup (Setup Time)}

Waktu setup, Ws, merupakan waktu yang diperlukan untuk menyiapkan kendaran, baik ketika akan berangkat dari lokasi maupun ketika kapal sampai dilokasi.

\section{Waktu Loading (Loading Time)}

Waktu loading WLD merupakan waktu untuk memasukkan muatan ke dalam kapal $z$ didepot. Waktu loading didapatkan dari jumlah produk yang diangkut, artinya semakin banyak yang dimuat maka waktu loading akan semakin lama.

$W L T=\frac{b[l[t, z, r, p]]}{L T}$

\section{Waktu Discharging (Dischraging Time)}

Waktu discharging DT adalah waktu membongkar muatan dari kapal yang dilakukan dilokasi pelanggan. Waktu discharging juga didapatkan dari jumlah produk yang dikeluarkan dari kapal, artinya semakin banyak yang diturunkan maka waktu dischargeing akan semakin lama. Kecepatan aliran barang per satuan waktu menentukan waktu loading dan discharging yang diperlukan.

$W D T=\frac{b[l[t, z, r, p]]}{D T}$ 
Waktu penyelesaian tur $=$ Waktu setup + Waktu loading + Waktu discharging + Waktu perjalanan + Waktu tunggu

$$
\begin{aligned}
C T_{[t]}= & W s \sum_{r=1}^{N R_{[t, z]}} \sum_{k=1}^{N L_{[t, z, r]}-1} L_{t, z, r, k}+ \\
& (W D T+W L T) \sum_{r=1}^{N R_{[t, z]}} \sum_{i=1}^{n} b_{L_{t, z, r} p}+ \\
& \sum_{r=1}^{N R} \sum_{[t, z]}^{N L_{[t, z, r]}-1} \tau_{\left[L_{t, z, r, k}\right],\left[L_{t, z, r, k+1}\right]}+ \\
& \sum_{r=1}^{N R[t, z]} \sum_{k=2}^{N L_{[t, z, r]}-1} W t_{L_{t, z, r, r}}
\end{aligned}
$$

Waktu penyelesaian tur kapal $z$ adalah sama dengan saat selesai suatu tur $J_{L[t, z, r, N L[t, z, r]}$.

$C T_{[t, z]}=J s_{L[t, z, r, N L[t, z, r]]}$

Saat keberangkatan dari lokasi pelanggan $J m_{L[t, z, r, k]}$ merupakan saat selesai pelanggan pada lokasi sebelumnya $J_{L[t, z, r, k-1] \text {. }}$

$J_{L[t, z, r, k]}=J_{S L[t, z, r,-1]}$

Saat tiba merupakan saat/jam keberangkatan kapal ditambah dengan waktu perjalanan kapal.

$J t_{L[t, z, r, k]}=J m_{L[t, z, r]}+W p$

Waktu tunggu terjadi bila saat kedatangan kapal pada suatu lokasi lebih kecil dari pada waktu buka pelayanan atau didefinisikan sebagai kedatangan mendahuli jam buka operasi pada suatu lokasi pelanggan.

$W t L[t, z, r, k]=$
$\left\{\begin{array}{r}b_{i}^{h}-J t L[t, z, r, k], \quad b_{i}^{h} \geq J t L[t, z, r, k] \\ 0, \quad b_{i}^{h}<J t L[t, z, r, k]\end{array}\right.$

\section{Horison Perencanaan (Planning Horison)}

Horison perencanaan ini membatasi total waktu penyelesaian tur. Panjang horison perencanaan dinotasikan dengan $H$. CT $[t, z]$ completion time untuk tur $t$ kendaraaan $z$ tidak boleh melebihi horison perencanaannya.

$C T_{[t, z]} \leq H$

Sehingga Total Completion Time (TCT) merupakan hasil penjumlahan dari semua completion time sumua tur $t$ yang dibutuhkan sebagai solusi.

$T C T=\sum_{t=1}^{N T} C T_{[t, z]}$

\section{Range of Completion Time}

Range of completion time merupakan perbedaan antara waktu penyelesaian maksimum dan minimum yang digunakan sebagai ukuran keseimbangan waktu penyelesaian tur.
$R C T=\left\{\begin{array}{r}\operatorname{Max}\left\{C T_{[t, z]}\right\}-\operatorname{Min}\left\{C T_{[t, z]}\right\}, N T>2 \\ 0, N T=1\end{array}\right.$

Pengembangan teknik pemecahan model ini diawali dengan menentukan algoritma yang akan digunakan untuk menyelesaikan masalah pada penelitian ini. Algoritma yang digunakan adalah mengembangkan algoritma sequential insertion dengan teknik Local Search. Algoritma sequential insertion ini membangun solusi yang layak dengan cara berulang kali mencoba memasukkan pelanggan yang belum masuk dalam rute manapun kedalam bagian sementara dari rute yang terbentuk saat ini. Isu yang muncul pada algoritma ini adalah pemilihan pelanggan yang belum masuk dalam rute manapun untuk disisipkan dan pemilihan lokasi tempat penyisipan pelanggan. Kelebihan dari algoritma Sequential insertion adalah akan berusaha menghasilkan jumlah kapal (tur) sekecil mungkin dengan memanfaatkan kapasitas kapal sebanyak mungkin, tetapi tentunya perlu dianalisis lebih lanjut tentang perilaku algoritma terhadap batasan-batasan yang terlibat dalam sistem ini. Teknik Local Search dimulai dari solusi awal dan berakhir pada minimum lokal yang tidak memungkinkan terjadinya perbaikan lagi.

Langkah-langkah berikut ini merupakan konstruksi penyelesaian yang telah dibangun berdasarkan notasi matematis.

\section{Langkah 0}

Inisiasi: $N=N ; \quad N T=0 ; N V=0 ; T C T=0$; $\mathrm{Z}=1$

Lanjutkan ke Langkah 1

\section{Langkah 1}

Tetapkan: $t=1 ; r=1 ; N T z=N T z+1$

$$
\begin{aligned}
& N R[t z]=1 ; N L[t, z, r]=2 \\
& L[t, z, r, 1]=L[t, z, r, N L[t, z, r]]=0 \\
& b[t, z, r, p]=0, \forall p \\
& C T[t, z]=0
\end{aligned}
$$

Lakukan pengecekan demand, jika demand sudah terpenuhi lanjutkan ke Langkah 9, jika tidak lanjutkan ke Langkah 2

\section{Langkah 2}

Untuk $i \in N$, coba masukkan setiap $i$ diantara $(k$, $k+1)$ untuk $k=1, \ldots, N L[t, z, r]-1$.

Tetapkan: $J m_{L[t, z, r, k]}=0 ; W p=\tau_{[L[t, z, r, k],[L[t, z, r, k+1]]}$

$$
J t_{[[t, z, r, k]}=0 ; W t_{L[t, z, r, k]}=0
$$

$W s_{L[t, z, r, k]}=$ input parameter

$W L T=\frac{b[L[t, z, r, p]]}{L T}$

$W D T=\frac{b[L[t, z, r, p]]}{D T}$ 


$$
\begin{aligned}
& J S_{L[t, z, N L[t, z, r]}=J m_{L[t, z, r, k]}+W p+J t_{L[t, z, r, k]}+ \\
& W t_{L[t, z, r, k]}+W s_{L[t, z, r]}+W L T+W D T \\
& C T[t, z]=J s_{L[t, z, N L L[t, z, r]]} \\
& \text { Jika CT[t,z]<H, Honjutkan ke Langkah } 8 . \\
& \text { Jika } C T[t, z]>\mathrm{H},
\end{aligned}
$$

Tetapkan pilih $i^{*}$ atau $\left.L_{[t, z, r, N L[t, z, r]}\right]^{*}$ yang memberikan waktu penyelesaian tur terpendek $C T[t, z]$ dan lanjutkan ke Langkah 3.

\section{Langkah 3}

Jika $q\left[i^{*}, p\right] \leq Q[p]$ untuk $\forall p$,

kemudian tetapkan $N=N-\left\{i^{*}\right\}$.

$$
\begin{aligned}
& Q[p]=Q[p]-q\left[i^{*} p\right], \forall p \\
& b[L[t, z, r, p]]=b[L[t, z, r, p]]+q\left[i^{*} p\right], \forall p \\
& N L[t, z, r]=N L[t, z, r]+1 \\
& L[t, z, r, 1]=L[t, z, r, N L[t, z, r]]=0 \\
& L[t, z, r, N L[t, z, r]-1]=i^{*}
\end{aligned}
$$$$
\text { maka permintaan } q\left[i^{*}, p\right] \text { sudah terpenuhi }
$$$$
\text { semua }
$$$$
q\left[i^{*}, p\right]=0
$$$$
\text { Jika } q\left[i^{*}, p\right] \geq Q[p] \text { untuk } \forall p \text { (split delivery) }
$$$$
\text { maka } q\left[i^{*}, p\right] \text { belum terpenuhi semua }
$$$$
q\left[i^{*}, p\right]=q\left[i^{*}, p\right]-Q[p]
$$

kemudian tetapkan $N=N$ yang baru. Lanjutkan ke langkah 4

\section{Langkah 4}

Jika $N \neq \varnothing$, lanjutkan ke Langkah 5. Sebaliknya lanjutkan ke Langkah 9

\section{Langkah 5}

Untuk $i \in N$, coba masukkan setiap $i$ diantara $(k$, $k+1)$ untuk $k=1, \ldots, N L[t, z, r]-1$.

Tetapkan: $J m_{L[t, z, r, k]}=J s_{L[t, z, r, k-1]}$

$$
\begin{aligned}
& W p=\tau[L[t, z, r, k],[[[t, z, r, k+1]] \\
& J t_{L[t, z, r, k]}=J_{L[t, z, r, k]}+W p \\
& W t L[t, z, r, k] \\
& =\left\{\begin{array}{r}
b_{i}^{h}-J t L[t, z, r, k], \quad b_{i}^{h}>J t L[t, z, r, k] \\
0, \quad b_{i}^{h}<J t L[t, z, r, k]
\end{array}\right. \\
& W s L[t, z, r, k]=\text { input parameter } \\
& W L T=\frac{b[L[t, z, r, p]]}{L T} \\
& W D T=\frac{b[L[t, z, r, p]]}{D T} \\
& J S_{L[t, z, r, N L[t, z, r]]}=J m_{L[t, z, r, k]}+W p+J t_{L[t, z, r, k]}+ \\
& W t_{L[t, z, r, k]}+W s_{L[t, z, r, k]}+W L T+W D T \\
& \text { Update CT[t,z] }=J_{L[t, z, r, N L[t, z, r]}
\end{aligned}
$$

Jika $C T[t, z]<\mathrm{H}$ dan $q\left[i^{*}, p\right] \leq Q[p]$, lanjutkan ke Langkah 6. Jika $C T[t, z]<\mathrm{H}$ dan $q\left[i^{*}, p\right] \geq Q[p]$, lanjutkan ke Langkah 7. Jika $C T[t, z]>\mathrm{H}$, lanjutkan ke Langkah 8.

\section{Langkah 6}

Pilih $i^{*}$ dan lakukan insersi pada posisi $\left(k^{*}, k^{*}+1\right)$ yang memberikan waktu penyelesaian tur terpendek $C T[t, z]$.
Jika $q\left[i^{*}, p\right] \leq Q[p]$ untuk $\forall p$, kemudian tetapkan $N$ $=N-\left\{i^{*}\right\}$.

$$
\begin{aligned}
& N L[t, z, r]=N L[t, z, r]+1 \\
& Q[p]=Q[p]-q\left[i^{*} p\right], \forall p \\
& b[L[t, z, r, p]]=b[L[t, z, r, p]]+q\left[i^{*} p\right], \forall p \\
& L\left[t, z, r, k^{*}\right]=i^{*}
\end{aligned}
$$

maka permintaan $q\left[i^{*}, p\right]$ sudah terpenuhi semua

$q\left[i^{*}, p\right]=0$

Jika $q\left[i^{*}, p\right] \geq Q[p]$ untuk $\forall p$ (split delivery) maka $q\left[i^{*}, p\right]$ belum terpenuhi semua $q\left[i^{*}, p\right]=q\left[i^{*}, p\right]-Q[p]$ kemudian tetapkan $N=N$.

Update posisi urutan $L[t, z, r, m]$ untuk $m=k^{*}+1, \ldots$, $N L[t, z, r]$. Update $C T[t, z]=J_{L[t, z, r, N L[t, z, r]]}$. Lanjutkan ke Langkah 4.

\section{Langkah 7}

$$
\begin{aligned}
& r=r+1 \\
& N R[t, z]=N R[t, z]+1 \\
& N L[t, z, r]=2 \\
& L[t, z, r, 1]=L[t, z, r, N L[t, z, r]]=0 \\
& b[t, z, r, p]=0, \forall p
\end{aligned}
$$

Lanjutkan ke Langkah 1.

\section{Langkah 8}

$$
\begin{aligned}
& t=t+1 \\
& r=1 \\
& N T z=N T z+1 \\
& N R[t, z]=1 \\
& N L[t, z, r]=2 \\
& L[t, z, r, r]=L[t, z, r, N L[t, z, r]]=0 \\
& b[t, z, r, p]=0, \forall p \\
& C T[t, z]=0
\end{aligned}
$$

Lanjutkan ke Langkah 1.

\section{Langkah 9}

Tetapkan

$$
\begin{aligned}
& N V=N T z \\
& T C T=\sum_{t=1}^{N T z} C T_{[t, z]} \\
& R C T=\operatorname{Max}\left\{C T_{[t, z]}\right\}-\operatorname{Min}\left\{C T_{[t, z]}\right\} \\
& Z=z+1
\end{aligned}
$$

Jika $z \leq Z$ maka lanjutkan ke Langkah 1

Jika $z>Z$ maka lanjut ke Langkah 10

Algoritma ini berhenti jika nilai jenis kapal $z$ telah melebihi total jumlah jenis kapal yang ada $Z$, artinya perhitungan telah dilakukan untuk semua jenis kapal.

\section{Langkah 10}

Tetapkan $f(\theta)$ * TCD

Stop. 
Algoritma ini mampu memberi hasil yang memuaskan dan dari algoritma yang dibangun proses perhitungan sudah mampu menangani criteria-kriteria yang menjadi pertimbangan pada model VRP ini.

\section{Hasil dan Pembahasan}

\section{Contoh Numerik}

Data selengkapnya pada penelitian ini diambil dari penelitian sebelumnya yaitu pada penelitian Arvianto [9]. Tabel 1 merupakan data permintaan bahan bakar selama 7 hari, dan data heteregenous fleet dipilih kapal tanker dengan kapasitas $8.750 \mathrm{kl}$, $4.700 \mathrm{kl}$, dan $2.000 \mathrm{kl}$.

Tabel 2 merupakan data waktu perjalanan yang telah dikonversi dari titik koordinat pada peta sebenarnya. Tabel 3 merupakan data biaya yang terlibat dalam peneltian ini.

Langkah selanjutnya adalah menentukan besarnya nilai bobot yang akan digunakan dalam perhitungan fungsi beban kerja dan fungsi biaya. Untuk besarnya bobot yang digunakan adalah 1.000 .000 untuk bobot jumlah kapal (NV), 10.000 untuk TCT, dan 10 untuk faktor RCT, dan bobot ini mengikuti data Yudistira et al. [10]. Proses perhitungan mengikuti algoritma sequential insertion yang telah dikembangkan.

Berdasarkan hasil perhitungan untuk semua kapal yang tersedia, terdapat 3 alternatif solusi untuk mendistribusikan BBM ke pelanggan di Nusa Tenggara Timur. Dari 3 alternatif solusi yang dibuat, maka yang terpilih adalah penggunaan kapal Tanker $4.700 \mathrm{kl}$. Pada penggunaan tanker ini didapat hasil bahwa untuk melayani kebutuhan semua pelanggan, dibutuhkan 2 kali tur dengan 2 buah tanker dengan total waktu pelayanan adalah 284,05 jam, fungsi beban kerja sebesar 4.904.625,83, dan fungsi biaya sebesar Rp 1.972.930.000,00. Hal yang cukup menarik adalah terpilihnya kapal tanker bekapasitas sedang, hal ini menunjukkan bahwa adanya kapal kapasitas besar akan mengakibatkan waktu loading lebih lama yang berarti jadwal keberangkatan menjadi lebih lama. Hal ini dapat memicu besarnya waktu tunggu kapal, besarnya waktu tunggu muncul akibat kondisi multipletime windows customer. Kondisi inilah yang memicu mengapa kapal tanker kapasitas besar menjadi tidak optimal, hal tersebut juga terjadi pada kapal kapasitas kecil. Situasi input parameter yang berbeda akan sangat mempengaruhi solusi akhir perhitungan.

Pada fungsi biaya, juga mengkibatkan adanya selisih biaya yang sangat besar antara 2 turnya, yaitu sebesar Rp 73.650.000,00. Adanya selisih yang cukup besar ini dipengaruhi oleh jumlah rute yang dilayani pada tur 1 lebih banyak 2 pelanggan dibanding tur 2, sehingga akan mempengaruhi besarnya biaya bahan bakar, loading unloading, retribusi, dan gaji operator kapal. Semakin banyak rute yang dilayani, maka keempat komponen biaya semakin besar.

Dengan selisih 2 pelanggan akan mengakibatkan adanya perbedaan biaya bahan bakar untuk 439 kilometer yang setara dengan $\mathrm{Rp} 65.850 .000,00$, biaya loading unloading sebesar Rp 6.000.000,00, biaya retribusi sebesar Rp 1.000.000,00, dan gaji operator kapal sebesar Rp 800.000,00. Fungsi tertimbang dibuat untuk mengetahui kecenderungan prioritas utama pada proses minimasi, tetapi hal yang paling umum adalah minimasi jumlah kapal karena ongkos sewa atau pembelian yang sangat dominan, tentunya hal ini harus disesuaikan dengan preferensi sistem.

Berdasarkan Tabel 4 menunjukkan bahwa dengan menaikkan kapasitas kapal tidak akan menjamin bahwa jumlah kapal yang digunakan dalam tur (NV) akan semakin sedikit, dan nilai fungsi beban kerja serta fungsi biaya semakin menurun. Hal ini dapat dilihat berdasarkan beberapa hal, antara lain:

Untuk kapal, hal yang mempengaruhi adalah jumlah tur yang harus dilakukan untuk melakukan proses pengiriman barang, karena pada penelitian ini telah ditetapkan bahwa 1 tur membutuhkan 1 kapal, sehingga apabila ada 4 tur maka ia membutuhkan 4 kapal.

Tabel 1. Permintaan bahan bakar minyak selama 7 hari

\begin{tabular}{clccc}
\hline Node & $\begin{array}{c}\text { Nama } \\
\text { Pelabuhan }\end{array}$ & $\begin{array}{c}\text { Premium } \\
\text { (liter) }\end{array}$ & $\begin{array}{c}\text { Solar } \\
\text { (liter) }\end{array}$ & $\begin{array}{c}\text { Minyak tanah } \\
\text { (liter) }\end{array}$ \\
\hline 001 & Atapupu & 287000 & 371000 & 378000 \\
002 & Dili & 350000 & 183750 & 905800 \\
003 & Kalabahi & 49000 & 112000 & 105000 \\
004 & Larantuka & 105000 & 210000 & 210000 \\
005 & Maumere & 219100 & 241500 & 344400 \\
006 & Reo & 119000 & 401100 & 337400 \\
007 & Ende & 160300 & 273000 & 312200 \\
008 & Waingapu & 119000 & 196000 & 280000 \\
\hline
\end{tabular}

Tabel 2. Data waktu perjalanan antar pelabuhan (jam)

\begin{tabular}{rrrrrrrrr}
$\mathbf{0 0 0}$ & & & & & & & & \\
11,8 & $\mathbf{0 0 1}$ & & & & & & & \\
18,0 & 5,5 & $\mathbf{0 0 2}$ & & & & & & \\
14,0 & 6,3 & 96 & $\mathbf{0 0 3}$ & & & & & \\
13,0 & 12,9 & 17,5 & 11,8 & $\mathbf{0 0 4}$ & & & & \\
21,8 & 29,5 & 25,5 & 19,4 & 12,0 & $\mathbf{0 0 5}$ & & & \\
34,8 & 29,9 & 32,0 & 27,4 & 21,8 & 12,4 & $\mathbf{0 0 6}$ & & \\
14,0 & 19,2 & 24,0 & 18,5 & 9,3 & 9,3 & 25,2 & $\mathbf{0 0 7}$ & \\
20,1 & 26,5 & 31,1 & 19,8 & 25,4 & 25,4 & 13,5 & 9,9 & $\mathbf{0 0 8}$ \\
\hline
\end{tabular}


Tabel 3. Konstanta biaya perhitungan manual

\begin{tabular}{clr}
\hline No & \multicolumn{1}{c}{ Jenis konstanta } & Besar biaya (Rp) \\
\hline 1. & Biaya tetap kendaraan & \\
& Tanker 6.500 & $1.800 .000 .000,00$ \\
& Tanker 3.500 & $800.000 .000,00$ \\
& Tanker 1.500 & $550.000 .000,00$ \\
2. Biaya bahan bakar per km & $150.000,00$ \\
3. Akomodasi perjalanan per hari & $40.000,00$ \\
4. Gaji supir per rute & $400.000,00$ \\
5. Biaya retribusi perjalanan & $500.000,00$ \\
6. Biaya Loading dan Unloading & $1.500 .000,00$ \\
\hline
\end{tabular}

Untuk TCT dipengaruhi oleh lamanya penyelesaian semua tur yang dijalani. Padahal, lamanya tur yang dijalani sangat dipengaruhi oleh kapal yang digunakan, yaitu apabila kapal yang digunakan kapasitasnya semakin besar waktu yang dibutuhkan juga semakin besar. Kapal yang lebih besar membutuhkan waktu yang lebih lama untuk melakukan loading produk, sehingga akan mempengaruhi waktu ke-berangkatan awal dari gudang. Selain itu, TCT juga sangat dipengaruhi oleh waktu kedatangan kedaraan di tempat pelanggan. Pada kasus kapal $8.750 \mathrm{kl}$, selain disebabkan oleh jam berangkat yang lebih lama, juga disebabkan karena banyak kapal yang tiba pada saat jam tutup pelanggan, sehingga kapal harus menunggu sampai jam buka.Faktor multiple time windows akan sangant berpengaruh pada kasus ini.

Untuk fungsi tertimbang, hal yang mempengaruhinya adalah NV dan TCT (Total Completion Time) dalam melakukan tur tersebut. Bobot untuk NV adalah 1.000.000, sehingga semakin banyak NV, maka nilainya juga semakin besar. Untuk bobot TCT meskipun hanya 10.000 , tapi nilai TCT nya juga sangat besar, sehingga nilai fungsi beban kerjanya juga akan semakin besar.

Tabel 4. Rekapitulasi hasil perhitungan semua jenis tanker

\begin{tabular}{|c|c|c|c|c|c|c|c|c|}
\hline $\begin{array}{l}\text { Kapasitas } \\
\text { (kl) }\end{array}$ & Rute & $\begin{array}{c}\mathrm{CT} \\
\text { (jam) }\end{array}$ & $\begin{array}{l}\mathrm{RCT} \\
\text { (jam) }\end{array}$ & \multicolumn{2}{|c|}{ Fungsi tertimbang $(f(\Theta))$} & $\begin{array}{c}\text { Jarak tempuh } \\
(\mathrm{km})\end{array}$ & \multicolumn{2}{|c|}{ Fungsi minimasi biaya (Rp) } \\
\hline \multirow{3}{*}{8750} & $\mathrm{~T} 1=7-5-4-3$ & 145,33 & 22,67 & $2.453 .526,7$ & & 872 & $1,947,240,000$ & \\
\hline & $\mathrm{T} 2=2-1-8$ & 153,07 & 14,93 & $2.530 .849,3$ & \multirow[t]{2}{*}{$7.201 .259,58$} & 926 & $1,951,440,000$ & \multirow[t]{2}{*}{5.799 .900 .000} \\
\hline & $\mathrm{T} 3=6$ & 121,64 & 46,36 & $2.216 .863,6$ & & 644 & $1,901,220,000$ & \\
\hline \multirow{2}{*}{4700} & $\mathrm{~T} 1=7-8-5-4-3$ & 145,33 & 22,67 & 2.453.526,7 & \multirow{2}{*}{$4.904 .625,83$} & 1.353 & $1,023,290,000$ & \multirow{2}{*}{1.972 .930 .000} \\
\hline & $\mathrm{T} 2=1-2-6$ & 145,09 & 22,91 & $2.451 .129,1$ & & 914 & $949,640,000$ & \\
\hline \multirow{4}{*}{2000} & $\mathrm{~T} 1=8-6-4-3$ & 128,69 & 39,31 & $2.287 .293,1$ & \multirow{4}{*}{$7.558 .504,66$} & 1.245 & $753,070,000$ & \multirow{4}{*}{2.658 .640 .000} \\
\hline & $\mathrm{T} 2=5-7-4$ & 96,04 & 71,96 & $1.961 .119,6$ & & 748 & $674,500,000$ & \\
\hline & $\mathrm{T} 3=1-4$ & 71,61 & 96,39 & $1.717 .063,9$ & & 458 & $626,860,000$ & \\
\hline & $\mathrm{T} 4=2$ & 59,19 & 108,81 & $1.592 .988,1$ & & 333 & $604,210,000$ & \\
\hline
\end{tabular}

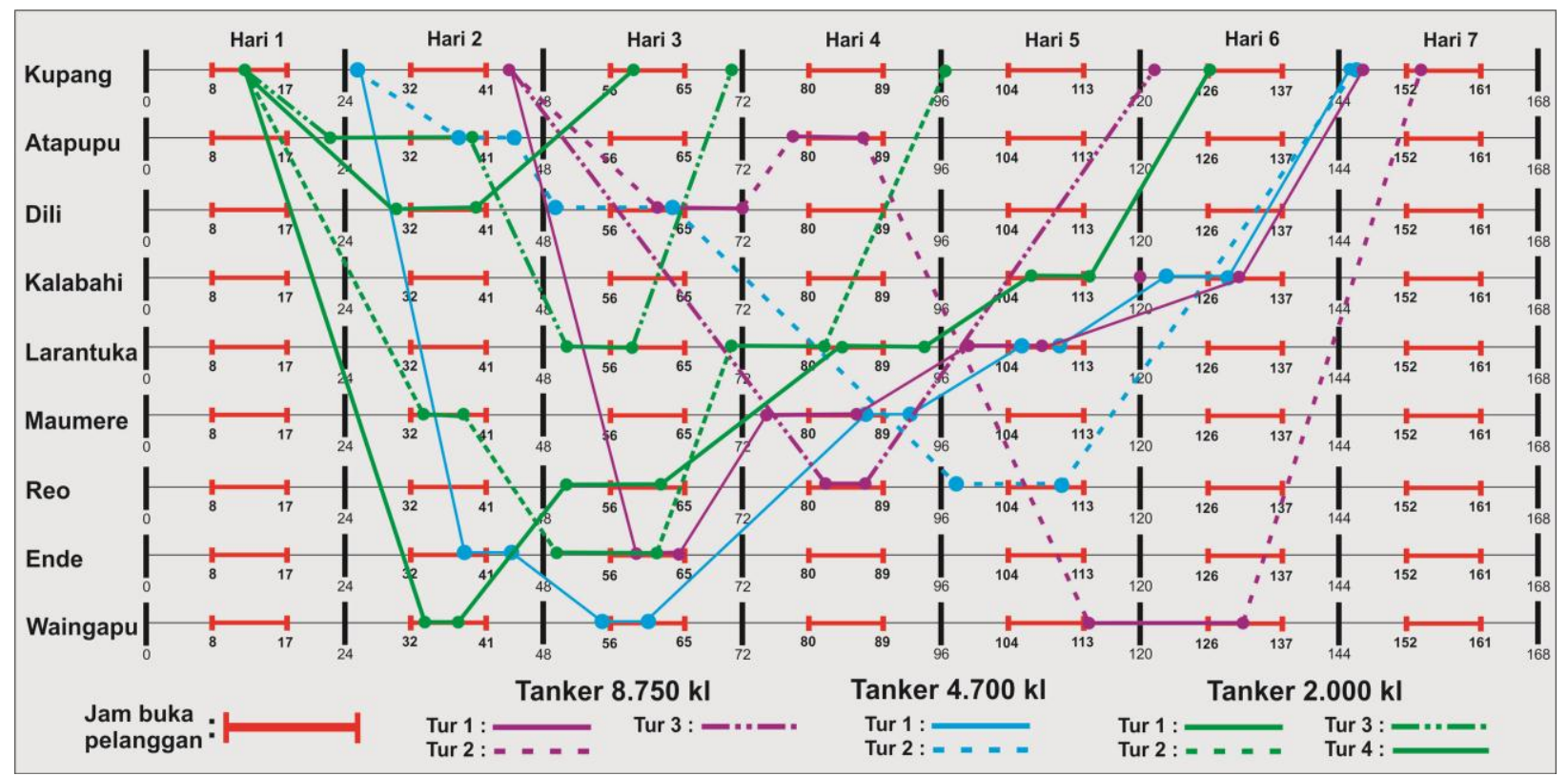

Gambar 2. Waktu penyelesaian pengiriman produk 
Untuk fungsi biaya, hal yang mempengaruhinya, yaitu besarnya biaya tetap untuk jenis kapal. Semakin besarnya kapasitas kapal yang dipakai, maka biaya tetap kapal juga besar. Selain biaya sewa kapal, biaya bahan bakar juga sangat dominan pada perhitungan fungsi ini, semakin jauh jarak tempuhnya maka akan membutuhkan biaya bahan bakar yang semakin banyak pula. Semakin banyak tur dan rute pelanggan yang harus dijalankan akan sebanding dengan jumlah kapal yang diperlu-kan maka fungsi biaya juga akan meningkat.

Fungsi biaya merupakan fungsi tujuan baru yang ditambahkan dalam penelitian ini. Fungsi biaya ini bertujuan untuk mengetahui berapa biaya yang kita butuhkan untuk melakukan pendistribusian produk ke pelanggan. Fungsi biaya ini dipengaruhi oleh beberapa fakto, tetapi paling utama adalah pada saat bobot NV menjadi hal yang paling diprioritaskan, maka nilai TCD akan dipengaruhi secara signufikan. Inputan faktor biaya didapatkan sesuai dengan biaya yang dibutuhkan pada saat proses pendistribusian.

Dapat disimpulkan bahwa besarnya nilai fungsi beban kerja dan fungsi biaya nantinya sangat bergantung pada perhitungan hasil pemilihan kapal. Tidak ada jaminan bahwa semakin kecil kapasitas kapal yang akan digunakan akan menjamin biaya yang dikeluarkan juga kecil, karena yang sangat berperan dalam perhitungan beban kerja serta biaya ini adalah total waktu yang ia dibutuhkan untuk menyelesaikan semua tur, baik itu waktu loading dan unloading produk, waktu mulai keberangkatan, waktu tunggu, serta waktu sampai di pelanggan.

Gambar 2 menggambarkan adanya perbedaan waktu mulai pelayanan untuk tiap jenis kapal. Diketahui bahwa kecepatan muat produk adalah sama, yaitu $200 \mathrm{kl} / \mathrm{jam}$, yang berbeda adalah jumlah produk yang dimuat untuk masing-masing kapal, sehingga waktu mulai dari masing-masing tanker adalah tidak bersamaan, yaitu tanker $2.000 \mathrm{kl}$ pada jam ke-12, tanker $4.750 \mathrm{kl}$ pada jam ke-25, dan tanker $8.750 \mathrm{kl}$ pada jam ke-45. Adanya perbedaan waktu mulai (waktu berangkat dari depot) ini disebabkan oleh adanya jumlah produk yang harus dimuat ke dalam kapal, sehingga makin banyak produk yang harus dimuat, maka waktu yang dibutuhkan semakin lama.

Oleh karena itu dibutuhkan suatu perhitungan yang tepat sesuai dengan alokasi jumlah produk yang akan dikirimkan dan kapasitas kapal yang dimilikinya, baik kapasitas total maupun pembagian kompartemennya karena akan mempengaruhi besarnya waktu yang dibutuhkan secara signifikan.

\section{Simpulan}

Berdasarkan penelitian yang telah dilakukan, dapat ditarik kesimpulan bahwa model VRP dengan varian baru heterogenenous fleet yang telah dibuat dalam penelitian ini sudah mampu diterapkan pada kondisi nyata yang telah mempertimbangkan batasan jam buka dan tutup pelanggan, jumlah produk lebih dari satu, serta ketersediaan kapal yang bervariasi jenis dan kapasitas muatannya (heterogeneous fleet, split delivery, multi products and compartements, multiple trips, dan multiple time windows).

Penyusunan dan penentuan urutan pelanggan berdasarkan penyusunan alternatif rute yang ada, kemudian dipilih berdasarkan ketersediaan jumlah kapasitas kapal dan total waktu pelayanan yang paling minimal, sehingga akan didapatkan solusi dengan waktu pelayanan terpendek, namun dengan jumlah maksimal pelanggan dalam tur. Solusi yang dihasilkan juga tidak melanggar batasan kapasitas kapal, jam pelayanan pelanggan, serta periode perencanaan keseluruhan.

Selain dapat menyelesaikan kasus VRP sesuai dengan karakteristik penelitian ini, model yang telah dibuat juga mempunyai kemampuan untuk memecahkan kasus VRP dengan varian single product and compar-tement, single time windows, dan homogeneous fleet.

Adanya perubahan parameter inputan pada penelitian ini juga dapat mempengaruhi hasil dari perhitungan. Tiap parameter akan mempengaruhi proses perhitungan yang akan dijadikan alternatif solusi.

\section{Daftar Pustaka}

1. Bodin, L., Golden, B., Assad, A., and Ball, M., Routing and Scheduling of Vehicles and Crews. The State of the Art, Computer and Operations Research, 10, 1983, pp. 63-211.

2. Gendreau, M., Taillard, E.D., and Laporte, G., Vehicle Routing Problem with Multiple Use of Vehicles, Journal of the Operation Research Society, 36(3), 1997, pp. 919-935.

3. Braysy, O., and Gendreau, M., Genetic Algorithms for the Vehicle Routing Problem with Time Windows, Arpakannus, 1, 2001, pp.33-38.

4. Belmecheri, F., Prins, C., and Yalaoui, F., Particle Swarm Optimization Algorithm for a Vehicle Routing Problem with Heterogeneous Fleet, mixed Backhauls, and Time Windows. 24th IEEE International Parallel and Distributed Processing Symposium, Atlanta, GA, USA, 6 Pages, 2010. 
5. Belfiore, P., and Yoshizaki, Scatter Search for a Real-Life Heterogeneous Fleet Vehicle Routing Problem with Time Windows and Split Deliveries in Brazil, European Journal of Operational Research,199(3), 2009, pp. 750-758.

6. Subramanian, A., and Huachi P., A Hybrid Algorithm for the Heterogeneous Fleet Vehicle Routing Problem, European Journal of Operational Research, 221(2), 2012, pp. 285-295.

7. Suprayogi, Algoritma Sequential Insertion untuk Memecahkan Vehicle Routing Problem with Multiple Trips and Time Windows, Jurnal Teknik dan Manajemen Industri, ITB, 23(3), 2003, pp. 30-46.
8. Imawati, D., Pemecahan Vehicle Routing Problem with Multiple Trips and Time Windows dengan Menggunakan Algoritma Local Search dan Simulated Annealing, Tugas Sarjana Teknik Industri ITB, 2004.

9. Arvianto, A., Teknik Local Search untuk Pemecahan Masalah Rute dan Jadwal Kendaraan dengan Karakteristik Multiple Time Windows, Tesis Magister Teknik Indutri ITB, 2009.

10. Yudistira. T., Suprayogi, dan Halim, A.H., Algoritma Heuristik Penjadwalan Alat Angkut untuk Pendistribusian Produk Majemuk dengan Sumber Tunggal dan Destinasi Majemuk, Prosiding Seminar Sistem Produksi VI, 2003, pp. 573-586. 